\title{
A ciência odontológica, Sísifo e o "efeito camaleão"
}

Adauto Emmerich ${ }^{1}$ Luis David Castiel ${ }^{2}$

EMMERICH, A.; CASTIEL, L.D. Dentistry science, Sisyphus and the "chameleon effect". Interface - Comunic., Saúde, Educ., v.13, n.29, p.339-51, abr./jun. 2009.

Dentistry science is not separated from the social context with which it is connected. The authors describe dentistry science in the way it happens in the dental surgeons' educational process, examining the role of scientific knowledge and also the relations between this knowledge and the practice of its main actors in the division between public and private. In the transition period between academic education and the job market, the authors try to understand the reasons why knowledge is produced and transformed by the mimesis of the various dentistry roles given by the "chameleon effect". It is concluded that, in this transepistemic arena, controversy is normal, and the interest in its destiny is in our hands. The authors attempt to examine the matters of interest for dentistry and the society in a realistic way. If, when we are explaining these matters, we can apply them, perhaps we can overcome the "chameleon effect".

Keywords: Transepistemic arena. Dentistry science. Dentistry and society.
A ciência odontológica não está isolada do contexto social a que está vinculada. Este artigo descreve a ciência odontológica tal como ela acontece no processo de graduação dos cirurgiões-dentistas, fazendo uma crítica acerca do papel do conhecimento científico e das relações que apresenta com a prática dos seus principais atores na bifurcação pública e privada. A partir da formação acadêmica, no período de transição entre a Academia e o mercado de trabalho, procura entender as razões pelas quais o conhecimento é produzido e transformado pelo mimetismo dos vários papéis odontológicos dados pelo "efeito camaleão". Conclui que, nessa arena transepistêmica, a controvérsia é normal, e o interesse quanto ao seu destino está em nossas mãos. Procura ser realista e crítico quanto às questões de interesse para a Odontologia e a sociedade, se, ao explicá-las, pudermos aplicá-las e, quem sabe, superarmos o "efeito camaleão".

Palavras-chave: Arena transepisêmica. Ciência odontológica. Odontologia e sociedade.
${ }^{1}$ Graduado em Odontologia. Curso de Odontologia e Programa de Pós-Graduação em Saúde Coletiva, Universidade Federal do Espírito Santo. Av. Marechal Campos, 1468. Vitória, ES, Brasil. 29040-090 adautoemmerich@ terra.com.br

${ }^{2}$ Médico. Departamento de Epidemiologia, Escola Nacional de Saúde Pública, Fundação Oswaldo Cruz. 


\section{Introdução}

Quando criança, muitos de nós respondemos a uma pergunta do mundo dos adultos sobre o que queremos ser na vida. Mesmo sem pensar, algumas vezes, a resposta foi: "Quero ser médico!", ou "Quero ser marinheiro!", ou "Quero ser professor!". Esse diálogo simples, que até hoje se repete entre milhares de crianças todos os dias, revela um sentido inicial da vida humana para alguma atividade profissional com a qual um dia sonhamos. No campo da Saúde Coletiva, a Odontologia talvez seja uma das profissões menos citadas na infância, pelo estigma e imaginário social odontológico da "dor de dente" (Emmerich, 2000), sendo ainda associada a uma prática profissional cruenta que leva a pesadelos.

Mas é possível que cada um de nós se recorde de alguma intervenção odontológica a que fomos submetidos na infância e, sem dúvida, se lembre de algum cirurgião-dentista em especial. Ademais, existem fortes influências para a carreira de cirurgião-dentista, como a de uma profissão liberal (por enquanto?) e a de um sucesso e status profissional bastante promissor. A partir desse exemplo, há algo paradoxal: praticamente todos aqueles que alçam vôo a essa carreira nunca foram atendidos ou têm entendimento das ações em saúde bucal desenvolvidas pelo Sistema Único de Saúde (SUS). Essa interligação não faz parte dos seus contextos sociais de origem que, de alguma forma, contribuíram e consolidaram uma visão de mundo odontológico-preliminar.

Entretanto, os saberes e práticas sobre a boca foram constituídos socialmente, e o seu exercício desenvolveu-se em conexão com os acontecimentos gerais da sociedade, o que levou a profissão a um caminho relacionado com o seu confinamento institucional nas leis profissionais e no ensino (Warmling, Caponi, Botazzo, 2006). O fenômeno que, mais uma vez, circula - referência circulante - (Latour, 2001) nesse processo é a profunda individuação do trabalho odontológico, persistindo a visão de que a Odontologia é uma profissão que irá possibilitar ascensão social rápida aos que a ela se dedicarem.

Esses elementos contribuem para a formação da complexa identidade do cirurgião-dentista, que pode ser mais bem compreendida a partir da desagregação do sujeito moderno, daquilo que Hall (2005) considera como seu deslocamento para um "sujeito fragmentado". Na modernidade tardia, a identidade é algo formado ao longo do tempo, por meio de processos inconscientes, e não algo inato, existente na consciência no momento do nascimento, permanecendo sempre incompleta, sempre em processo de formação. Dentro desse contexto identitário, os indivíduos estão "mergulhados" em um processo contínuo de busca da sua identidade, construindo biografias que tecem diferentes partes de eus divididos (Hall, 2005).

Ao ingressar na Academia, os pretendentes à carreira de cirurgião-dentista trazem informações e subjetividades experienciadas nos contextos sociais de origem e, como exemplo, na atenção odontológica recebida. Neste caso, o "efeito camaleão" tem origem em tempos remotos da nossa existência e, para o cirurgião-dentista, é promovido coletivamente pelo contexto no qual as estruturas relacionais da "comunidade odontológica" estão incluídas, envolvendo: os segmentos de usuários e "pacientes-clientes", estudantes de odontologia, entidades classistas, mercado profissional e o complexo odontológico-industrial.

Com facilidade e rapidez, o cirurgião-dentista mimetiza-se de aparência, de comportamento, de atitudes ou de opiniões, de acordo com as circunstâncias e em decorrência de seus interesses e conveniências pessoais. Nesse processo, a "comunidade odontológica" é um conceito operacional na formação científica (cognitiva), social e cultural da identidade do cirurgião-dentista. Em grande parte dos ambientes das profissões de nível superior, deve ocorrer, em graus variáveis, esse "efeito camaleão" fazendo parte dos contextos laborais.

Essa figura de retórica que estamos utilizando para o entendimento da formação ontológica do cirurgião-dentista tem um significado objetivo e de contiguidade conceitual com o ingresso permanente de novos atores na "comunidade odontológica", desde o processo de formação na graduação; e, como metonímia, ajuda-nos a entender o que está mimetizado, implícito e interligado na sua formação ontológica e epistemológica. Por exemplo, uma vez que a Estratégia de Saúde da Família (ESF) vem se expandindo no Brasil como política da Atenção Básica à Saúde, há uma corrida desenfreada pelo coletivo de cirurgiões-dentistas a cursos de aperfeiçoamento e especialização nessa área para conseguir um emprego. Perguntamos: esse é o profissional de saúde ideal para o SUS? 
A competição entre Academia e mercado, adaptando a reflexão sobre o campo científico de Bourdieu desenvolvido por Hochman (2002), encontra-se condicionada pela estrutura social, na qual o "progresso da razão" resulta da competição por acumulação e reprodução de capital simbólico, que não é monetário e está relacionado a competência científica, prestígio ou honra. Essa prática científica é dinâmica, competitiva e plural, instável, na qual indivíduos concorrem pela produção de informações relevantes, que serão convertidas ou modificadas, e cujo resultado é sempre coletivo e indeterminado.

Latour (2000) considera que, quando nos aproximamos dos lugares onde são criados fatos e máquinas, entramos no meio das controvérsias. Quanto mais aumentamos o nosso foco de observação, mais as coisas se tornam controversas. Assim, quando nos dirigimos da vida "cotidiana" para a atividade científica, do homem comum para o de ciência, dos políticos para os especialistas, não nos dirigimos do barulho para o silêncio, da paixão para a razão, do calor para o frio. Vamos de controvérsias para mais controvérsias que se relacionam com um contexto social ambíguo de profunda crise de sentido e de fragilidade identitária.

Castiel (2004), ao referir-se ao mito de Dédalo para estudar a identidade cultural, a subjetividade e os riscos à saúde, menciona o estudo de AH Hawkins, ao considerar a dimensão mítica com três funções básicas: a primeira é a "integrativa", por dizer respeito a uma atividade sintetizadora da mente humana; a segunda, a "conectiva", por buscar a vinculação do indivíduo a contextos ampliados da cultura, procurando relacionar a "parte" com o "todo"; a terceira, a "metafórica", por alcançar o significado explícito sem processos explicativos racionalizantes. Assim, a produção de novos artefatos técnicos odontológicos e as suas interconexões labirínticas caracterizam-se pela produção incessante e engenhosa, com repercussões: na ampliação e na velocidade de circulação de trocas econômicas, na proliferação de estratégias de mediação comunicacional, na multiplicação e diluição das matrizes identitárias, nas ambiguidades generalizadas e na crise de sentido.

Este ensaio propõe-se a discutir, com conceitos e idéias assumidamente frágeis, as controvérsias e imprecisões relacionadas com a disputa (guerra) transepistêmica, os labirintos do "efeito camaleão" produzidos coletivamente na formação odontológica. Procuraremos desvelar criticamente a crise de sentido na Odontologia que, de alguma forma, se refere à diluição das matrizes identitárias dos cirurgiões-dentistas e às ambiguidades da sinuosa configuração do saber-fazer técnico odontológico. Além disso, desenvolveremos um processo de análise sobre as bases do conhecimento odontológico que vêm gerando uma prática distante de signos, como um cuidado integral para a saúde bucal, para além do caminho supostamente retilíneo e horizontal da razão e do conhecimento científico odontológico. Também questionamos: que desafios estão colocados para uma Integralidade no campo da Odontologia, e qual sua inter-relação com a saúde bucal coletiva?

Ao fazer uma descrição crítica da ciência odontológica tal como ela acontece no processo de graduação dos cirurgiões-dentistas, buscamos proceder a uma crítica a respeito do papel da "comunidade odontológica" e investigar que relações a comunidade apresenta com a prática da ciência odontológica. Com uma descrição analítica do período de transição entre a Academia e o mercado de trabalho, este estudo destina-se a entender as razões pelas quais o conhecimento é produzido e camaleonicamente transformado na estrutura social capitalista consumista. Latour (2006) considera que a crítica, de modo geral, não tem sido suficientemente crítica, apesar de todas as tentativas. O que acontece é que a realidade não se define pelas questões de fato, pois estas não são tudo o que nos dá a experiência, são parciais e apenas uma fração do que poderia também se chamar "estado de coisas".

Aqui vamos nos apoiar naquilo que consideramos como ferramenta descritiva poderosa, que se ocupa das questões de interesse (Latour, 2006), procurando transformar o impulso crítico no ethos de alguém que acrescente, ao invés de subtrair realidade e sentido às questões de fato da Odontologia contemporânea.

\section{O efeito camaleão e a saúde bucal coletiva}

Para ilustrar a metonímia "efeito camaleão" e as transformações dos atores odontológicos na "comunidade odontológica", usaremos a figura da bifurcação entre o público e o privado com um problema: onde começa o adoecimento humano? Sem querer forçar uma ironia ao responder, a 
Odontologia, nos últimos tempos, usou (e abusou), em seu discurso oficial, do slogan: "A saúde começa pela boca". Até hoje, na mídia televisiva, existe propaganda de clínicas odontológicas que divulgam uma "semiologia odontoestomatológica" que perpetua esse olhar apriorístico, como se definisse um diagnóstico fundamental sobre o adoecimento e a saúde do ser humano e o suprassumo da prática odontológica.

Esse discurso odontológico vem consolidando um território no corpo humano como sendo a área onde tudo começa na saúde-adoecimento não somente bucal, dando a entender, implícita e intencionalmente, que as relações intersubjetivas entre os sujeitos e as condições socioeconômicas não são signos constitutivos do processo saúde/doença. Representa um arroubo exagerado sem nenhuma evidência científica com questões de interesses subjacentes, muito de acordo com os tempos atuais, caracterizando a territorialidade anatômica do corpo e a sua morfologia (boca) com um olhar superficial, um "olhar anatômico".

A exaltação da Odontologia, "A saúde começa pela boca", consolidou um distanciamento e fragmentação da percepção do objeto odontológico como objeto coletivo. É como se a Odontologia tivesse pretensiosamente um domínio absoluto: do ser humano e da clínica odontológica que lhe é necessária, das suas categorias de doença, da saúde bucal, do normal, do patológico e de novas subjetividades advindas com o adoecimento (Canguilhem, 2007). Essa delimitação de uma área de atuação pela Odontologia perpetua a separação do objeto-boca do objeto corpo-social.

$\mathrm{Na}$ "comunidade odontológica", brotam as relações intersubjetivas do "efeito camaleão", com a socialização dos indivíduos, ocorrendo uma rede de troca de saberes, em todos os níveis, na qual a epistemologia odontológica se apresenta reivindicando os seus espaços. Como exemplo da relação das competências profissionais, o cuidador traz dentro de si um problema ontológico filosófico-existencial. Todo cuidador (profissional ativo), em alguma instância, é uma pessoa que é cuidada. A pessoa que é cuidada desde a sua infância pelo cuidador cirurgião-dentista, ao entrar na Faculdade de Odontologia, transforma-se em um cuidador. Ocorre, nesse momento, um processo de socialização, que é uma "odontologização do cuidador" em formação.

Essa "odontologização" apresenta laços e redes intrincadas e obscurecidas em nosso tecido socialodontológico, e é assunto por demais amplo para ser esgotado, neste momento, em suas conexões e interesses. Para exemplificar esses fatos (controvérsias) camaleônicos em outra dimensão, observemos o portal da Universidade de Brasília (UnB), Odontologia, tópico Guia de profissões (2008). Nele se lê que a idéia de escolher uma profissão para ganhar dinheiro ainda atrai muitos estudantes para os cursos de Odontologia. Ao argumentar sobre a crise do mercado de trabalho, os baixos preços pagos pelos convênios e os altos custos para se montar consultório, essa matéria tenta mostrar que o aspecto financeiro não deve ser o motivo principal para a escolha. Ao justificar que, mesmo diante dessa crise, há outras fortes razões para se optar pela profissão, esquece-se das tentações da Odontologia de mercado. Afirma, ainda, que a Odontologia pode ser considerada uma arte, e o cirurgião-dentista que preza pela qualidade realiza um trabalho artístico ao esculpir um dente, fazer uma obturação ou deixar uma arcada dentária esteticamente perfeita. No entanto, esse portal procura deixar claro que o objetivo do curso é preparar o futuro profissional para exercer um papel de interferência na situação da saúde bucal da população brasileira, com caráter social, refletindo uma preocupação com a comunidade, onde o aluno pode participar de projetos voltados para a promoção da saúde e da cidadania na sociedade.

As dubiedades assinaladas são faces de uma mesma moeda: o "efeito camaleão" na bifurcação da formação profissional voltada para a saúde bucal coletiva e a influência da Odontologia de mercado tendo, como pano de fundo, o homo economicus (Sennett, 2006) com o "progresso da razão" e seus dilemas existenciais. Essa constatação implica percebermos um terreno complexo em que uma ruptura com a prática odontológica hegemônica (Narvai, 2006) é algo que merece ser aprofundado epistemologicamente.

\section{O sujeito epistêmico coletivo}

Para responder às questões levantadas até o momento, vamos procurar entendê-las fazendo uma incursão na direção da construção de um sujeito epistêmico coletivo nas várias dimensões da "comunidade odontológica". 
Em primeiro lugar, a idéia de um sujeito epistêmico coletivo levanta a questão do contexto atual da significação da vida humana. Berger e Luckmann (2004) partem do pressuposto de que se operou uma transformação radical das condições básicas da vida humana, com uma nova constituição social do seu sentido nos tempos modernos, desembocando em uma crise sem par na história, e de que, para o entendimento das mudanças históricas atuais, devemos levar em consideração os pressupostos gerais e as estruturas básicas da significância da vida humana. Para esses autores, o sentido constitui-se na consciência humana: na consciência do indivíduo que se individualizou num corpo e se tornou pessoa por meio de processos sociais.

A consciência, a individualidade, a sociabilidade e a formação histórico-social da identidade pessoal do cirurgião-dentista são características essenciais, gestadas desde cedo nos indivíduos. Ao optar, em sua vida, pela carreira, o acadêmico, em conversas com profissionais, ou até com seu próprio cirurgiãodentista, esboça percepções éticas, estéticas, culturais e sociais que, na prática das disciplinas ensinadas e nas atividades extracurriculares (experiências), constroem a consciência nas múltiplas significâncias da experiência e da ação clínica e profissional na vida de cada um.

A consciência que a pessoa tem da sua profissão, no início ou na sua infância, se for tomada em si, não é nada ainda. Agora, caberia uma pergunta: e a consciência que um cirurgião-dentista tem da sua profissão, se vai ou não dedicar-se à saúde bucal coletiva? De modo geral, a consciência, para Berger e Luckmann (2004), existe somente quando se dirige a atenção para um objeto, gerando experiências que não ocorrem simples e independentemente, mas para as quais o eu dirige a sua atenção, e elas ganham um grau maior de definição temática, tornando-se experiências delineadas.

A tematização da corporalidade (boca) como objeto da prática odontológica, e não como objeto coletivo (social-humano), é uma percepção intencional constituída pelas diversas realizações de síntese da consciência, que aparecem em percepções, memórias ou imaginações desde muito cedo, e que irão amalgamando os desejos coletivos odontológicos e o seu magma de significações nas suas disciplinas. A partir do referencial da bucalidade, a saúde bucal não se esgota na forma clínica, pois não dá conta de uma abrangência epistemológica de infinitas possibilidades no propósito de recuperar o homem por inteiro (Botazzo, 2006).

Em segundo lugar, na sequência de disciplinas na graduação, no início do curso, os temas interrelacionados ainda não são significativos por si mesmos. É nesse início que se vai consolidar o cerne sobre o qual pode surgir o sentido-identidade do homo economicus e o "progresso da razão" do cirurgião-dentista. É quando, por exemplo, o acadêmico de Odontologia vai "estagiar em algum consultório odontológico" no qual as relações profissionais são entendidas como "semelhantes" ou "iguais" às do seu ambiente acadêmico. É assim que pode estar se constituindo o grau mais elementar da formação biotecnicista do cirurgião-dentista e do sentido da prática profissional na atualidade. $\mathrm{O}$ sentido nada mais é do que uma forma complexa de consciência: não existe em si, mas sempre possui um objeto de referência, é a consciência de que existe uma relação entre as experiências (Berger, Luchmann, 2004).

Predomina ainda uma prática odontológica de consultório e de quatro paredes, mesmo com algumas experiências de extensão em saúde bucal coletiva. Não se privilegia uma atenção à saúde bucal socialmente determinada, interdisciplinar e multiprofissional, como é necessária, por exemplo, para a ESF. Narvai (2003) descreve com muita clareza que, tradicionalmente, os cursos de Odontologia no Brasil possuem currículos direcionados para uma formação tecnicista, tendo uma prática clínica individualizada, biocêntrica, fragmentada e curativa, enfatizando o uso de tecnologias "de ponta".

Nesse caso, quando o profissional ingressa na ESF, praticamente não traz uma experiência duradoura, consistente, interdisciplinar e multiprofissional, que já tivesse acontecido na graduação, nos moldes e esquema de funcionamento derivados da lógica funcional da ESF, que fosse exercitada em uma clínica odontológica cujas disciplinas de interesse fossem uma prática preliminar e intercambiada com a necessidade social e epidemiológica da população, voltada para a Integralidade do cuidado.

As experiências humanas, segundo Berger e Luckmann (2004), situam-se na constituição subjetiva do sentido, que é a origem de todo acervo social do conhecimento, do reservatório histórico do sentido, do qual se nutre a pessoa nascida numa determinada sociedade e numa certa época. Como os problemas surgem no agir social interativo, também as soluções devem ser encontradas em comum, nas 
mais diversas formas, tornando-se acessíveis a outros grupos, propiciando novos instrumentos de trabalho, novas metodologias de acolhimento, construções de unidades de saúde mais funcionais e humanizadas e novas ações comunicativas para a saúde.

Em terceiro lugar, e aqui não podemos ser inocentes, entendemos que a modernidade tardia vem instituindo crescentemente procedimentos intervencionistas sobre os corpos (boca) dos indivíduos. $O$ epítome é o domínio da sedução que as emergentes biotecnologias odontológicas exercem sobre as mentes em formação dos acadêmicos, intermediadas pelas tentações do mercado de trabalho.

Com a tentativa de minimizar a lacuna existente entre o perfil atual do cirurgião-dentista e um profissional que atenda realmente às necessidades da população, o Governo Federal formulou uma política de reordenação na formação de recursos humanos, o Programa Nacional de Reorientação da Formação Profissional em Saúde (PRÓ-SAÚDE), fornecendo subsídios para um novo perfil profissional comprometido com a situação epidemiológica apresentada pela sua região de atuação. Esse programa, em suma, pressupõe a integração ensino-serviço, otimizando e qualificando os serviços à sociedade (Brasil, 2007). Muito bem: o paradoxo, no entanto, é que os profissionais da saúde bucal vêm secularmente sendo formados segundo o modelo educacional biomédico e flexneriano, não apresentando um perfil adequado para atuar no modelo de saúde vigente.

Mesmo com a implantação do PRÓ-SAÚDE, as mudanças, no campo do ensino odontológico voltado para a saúde bucal coletiva, precisam ser "combinadas" e pactuadas com interesse entre todos os atores envolvidos na clínica odontológica, para que as controvérsias, que são até naturais, sejam discutidas e superadas na medida do possível.

Por outro lado, Chaves e Miranda (2008) entendem que há uma crise decorrente da mudança de habitus - base instrumental analítica do autor Bourdieu (1996) - profissional dos cirurgiões-dentistas, em decorrência de sua inserção em um novo contexto de trabalho que é assalariado e de prestação de serviço na esfera pública, muito diverso do que fora sonhado inicialmente, uma atuação profissional essencialmente liberal. Apontam também, no campo em que desenvolveram o estudo, que há sinais e sintomas contraditórios sobre os desgastes ou a perda da aura do habitus de profissional liberal.

Bourdieu (1996) assinala, no seu conceito operacional, habitus como sendo um sistema aberto de disposições, ações e percepções que os sujeitos adquirem com o tempo em suas experiências sociais, tanto na dimensão material, corpórea, quanto simbólica, cultural, entre outras. Pretende superar a antinomia entre objetivismo, com a preponderância das estruturas sociais sobre as ações do sujeito, e subjetivismo, com a primazia da ação do sujeito em relação às determinações sociais (Socha, 2008). Nesse caso, o habitus do cirurgião-dentista é dado pela posição social do indivíduo que pensa e age nas mais variadas situações de sua prática profissional, traduzindo, dessa forma, estilos de vida, julgamentos políticos, morais e estéticos.

Santos $(2003 a, 2003 b)$ considera que a ciência moderna consagrou o homem como sujeito epistêmico, mas expulsou-o, tal como a Deus, como sujeito empírico. Assim, um conhecimento objetivo, factual e rigoroso não tolera a interferência dos valores humanos ou religiosos. Segundo o autor, foi dentro desse contexto que se construiu a distinção dicotômica sujeito/objeto. O "efeito camaleão" promovido pelo coletivo de sujeitos cirurgiões-dentistas assimila e envolve-se na referida distinção dicotômica sujeito/objeto, tornando-se, nesse sentido, dogmático.

O que a "comunidade odontológica" promove é uma dissociação da ciência odontológica quanto aos interesses ontológicos e epistemológicos do ponto de vista coletivo, naturalizando o processo saúde/doença. Um processo de desdogmatização da ciência odontológica se refere ao entendimento sobre o seu objeto, que vem a ser o próprio homem e sua realidade sociocultural, de forma que sujeito e objeto se veem confundidos (Botazzo, 2003).

Entretanto, a interação de professores-cientistas com os estudantes de Odontologia nos laboratórios, nas clínicas odontológicas, de uma forma mais dinâmica e mais instável, mais indeterminada e menos consensual, vai tornando esses atores mais abertos ao mercado de trabalho. As fronteiras entre o mercado de trabalho e a Academia, como produtora de biotecnologia e de novos profissionais, vão assim sendo estreitadas, até surgir aquilo que Hochman (2002), apoiado nos trabalhos de Karin KnorrCetina, denomina de arena transepistêmica. 
O produto da ciência não é o resultado da ação autônoma e isolada dos cientistas, mas, isto sim, impregnada e diluída pelo mercado de trabalho, que direciona e impõe a sua lógica, atendendo às expectativas e aos interesses das classes dominantes sobre o processo produtivo, a fim de garantir a sua hegemonia. Assim como Latour (2001), Knorr-Cetina, fazendo uma crítica ao "objetivismo", adere à perspectiva construtivista, que enxerga, nos produtos da prática científica, construções contextualmente específicas, que têm como características a situação contingente e a estrutura de interesse do processo pelas quais foram geradas.

Existe, dentro de uma "cortina de fumaça", um campo de disputas no qual a ciência odontológica é assimilada, sem que os participantes sejam devidamente municiados de pressupostos para uma efetiva ação. A ciência odontológica que está em jogo nessa guerra não é neutra e encontra-se, em sua maioria, no centro da arena ontológica formada. É no processo de graduação de novos cirurgiõesdentistas que se trava uma "batalha transepistêmica-ontológica", que não é muito bem definida e coletivamente assimilada, tendo a metonímia do "efeito camaleão" um desafio à sua contextualização.

Parece um game contínuo extremamente competitivo, sem tréguas e muitas vezes silencioso, no qual os atores envolvidos, novos alunos, professores, laboratórios anatômicos, projetos de extensão, pacientes e as tentadoras ofertas de novas biotecnologias e equipamentos odontológicos estão em ação, onde permanentemente as controvérsias são silenciosamente confrontadas. Moysés (2004) assinala, com muita propriedade, que, na graduação, são enfatizados os domínios cognitivos e instrumentais, com uma nítida ruptura epistemológica do conhecimento odontológico relacionado com uma separação, por oposição, da esfera pública e privada, promovendo, dessa forma, distorções na formação e representação social da prática odontológica, permeando as intersubjetividades.

Em quarto lugar, setores associativos da "comunidade odontológica", na disputa pela hegemonia do saber, na maioria das vezes, divulgam um discurso em que denotam preocupações com a problemática social-odontológica. Nesse caso, a nossa impressão é de que o discurso está profundamente dissociado de interesses coletivos, trazendo dentro de si uma visão elitista e fragmentada do objeto odontológicocoletivo. Um exemplo de maior magnitude são os Congressos Nacionais da Associação Brasileira de Odontologia (ABO), na agenda nacional 2006/2007. A agenda denominada Dental Calendar (2006) divulga temas oficiais de congressos relativos à área, como: Congresso de Odontologia Estética; Meeting de Estética em Odontologia; Saúde, Exército de Cidadania; A Odontologia como Ferramenta de Inclusão Social; Saúde Pública e Especialidades Odontológicas: direito da família; A Odontologia e a Proliferação de Novos Cursos: quem ganha? Odontologia: Excelência Profissional e Inclusão Social; Saúde Bucal: uma porta para a inclusão social; Papel das Especialidades na Saúde Bucal Contemporânea e Valorização Profissional.

Com a interação dos agentes cirurgiões-dentistas e estudantes de Odontologia nas estruturas odontológicas apresentadas, emerge sua ontologia ideológico-identitária entrelaçada com seu envolvimento nas várias instâncias da formação odontológica e os elementos epistemológicos estruturantes daquilo que chamamos de "comunidade odontológica".

Entretanto, o ator cirurgião-dentista, racional e maximizador de lucros relacionados com os modelos de economia capitalista, não é o único, pois a "comunidade odontológica" está voltada para o mercado, integrada pela competição desenfreada e pela necessidade de sobrevivência individual. Coexistem, nessa arena transepistêmica, a outra face do mercado, da Saúde Pública no Brasil, que se consolidou com a criação do SUS nos anos 1990, revelando o desafio da formação de um sujeito epistêmico coletivo para a saúde bucal coletiva.

Os vários papéis dados pela metonímia do "efeito camaleão" reforçam a idéia da influência do homo economicus e do "progresso da razão" no habitus das estruturas relacionais da "comunidade odontológica". Nessa arena, a controvérsia é normal e deve ser exercitada e discutida, pois, como esse é um exemplo do processo coletivo da construção de idéias e dos fatos odontológicos, o seu destino está em nossas mãos. 


\section{A ciência odontológica e a arte dentária}

As fronteiras entre o mundo do mercado e o dos praticantes da ciência odontológica vão-se diluindo e daí surgindo uma arena epistêmica interligada, dentro de si própria. Gayon (2006), ao analisar, com bastante propriedade, a epistemologia da Medicina, faz uma distinção entre ciência e arte, considerando que a prática médica ainda está presa ao technè. O conhecimento médico está voltado para a esperança de que o estado indesejável da doença possa ser previsto, melhorado, curado ou aliviado. Assim, ao contrário das outras ciências naturais, esse conhecimento está inteiramente submetido a uma arte de prevenir, aliviar ou curar.

O trabalho do filósofo alemão Wolfgang Weiland considera que foi a análise aristoteliana das noções de epistémè e de technè que permitiu conceber a distinção entre a ciência e a arte médica, e a tensão que essa distinção exprime. A ciência, conforme a definição aristotélica, é um modo de conhecimento que visa àquilo que é universal e necessário, enquanto a arte atua como disposição a produzir um conhecimento acompanhado de regra (Gayon, 2006).

Nesse sentido, pergunta-se: na atualidade, pode-se ainda qualificar a Odontologia como a de antanho "arte dentária" ? Achamos que sim: a arte dentária ainda é uma característica da clínica odontológica, na qual o cirurgião-dentista se coloca em contato com um paciente individualizado, com dor de dente, dentes tortos, dentes ausentes, com uma cientifização fragmentada que recolhe dos pacientes, por meio de exames radiográficos e clínicos, sinais e sintomas de alguma doença bucal.

O uso do flúor, como ação coletiva de promoção da saúde bucal no Brasil com o controle epidemiológico, a partir da experiência de Baixo Guandu (ES), em 1953 (Emmerich, 2003), o motor de alta rotação introduzido na clínica odontológica na segunda metade do século passado e, mais recentemente, o uso do laser e seus vários fins, e os implantes dentários transformaram ativamente a prática odontológica. Isso propiciou o avanço da dimensão tecnocientífica da Odontologia, com controle, diagnóstico e terapêutica para a cárie dentária, com o uso em grande escala do flúor tópico, com as investigações de novos materiais e a consolidação das resinas compostas como material restaurador dentário de excelência, e as cerâmicas sendo obviamente para quem tem acesso à Odontologia de mercado.

As escolhas epistêmicas realizadas pelos atores odontológicos, caracterizando a "arte dentária" atual, têm diferentes razões ideológicas e imaginárias, produzindo focos teóricos e metodológicos díspares. $\mathrm{O}$ conhecimento denso e complexo das disciplinas clínicas, desprovido de um conteúdo social do processo saúde/doença, caracteriza a Odontologia como uma arte imersa em uma arena epistêmica do vir-a-ser e de contingências. Essa característica comportamental peculiar tem um vínculo com o modelo de consumo capitalista globalizado, que é um estorvo às mudanças humanistas e sociais que o SUS exige e a que a Odontologia deve responder com uma formação voltada para a Integralidade. Para Hochman (2002), mais uma vez apoiando-se em Knorr-Cetina, a interação dos agentes nessa arena tem os seus interesses na bifurcação público-privada. Esses interesses são continuamente renovados, expandidos ou retrocedidos para a sua sobrevivência.

A influência dos interesses econômicos foi muito bem detectada no capitalismo atual por Sennett (2006), ao usar, como ilustração, os antigos atenienses, que costumavam separar o lugar onde faziam o pnyx , do espaço econômico central da cidade, a ágora. Essa separação reflete um postulado clássico do pensamento social, o de que a atividade econômica debilita a capacidade política das pessoas. Ao referir-se a Platão, explica que a lógica é simples, pois, para Platão, a economia opera no terreno da necessidade e da ganância, ao passo que a política deveria atuar na área da Justiça e do Direito.

Isso significa que a ação política e a imaginação política exigem certo grau de proteção da experiência econômica. Na sociedade da modernidade tardia, esse postulado assumiu outros contornos, mais ligados à vida cotidiana que à teoria, em função do próprio significado da palavra consumo, que pode ser uma paixão que se extingue na própria intensidade, pois, utilizando coisas, nós a estamos consumindo. Assim, a transformação do espaço social da clínica odontológica em relação ao mercado, com uma imposição econômica, produz uma forma diferente de socialização e de consumo.

A impressão que fica é de que estamos diante de uma corrida de consumo desenfreado pela informação e de uma concomitante persistência da prática odontológica centrada na "arte dentária". 
Para González (1997), não só se tem desagregado a biologia humana com as discutíveis superespecialidades, mas também tem-se potencializado muito mais a referida desagregação.

Sennett (2006) caracteriza esse processo como o da "sociedade da capacitação", pelo medo que o indivíduo tem de se tornar supérfluo ou de ficar para trás, considerando que a ética do trabalho se modificou e que as fronteiras entre consumo e política se misturam e se transfiguram e vão ao encontro do "progresso da razão".

A importância da prática odontológica clínica com enfoque epidemiológico e social, para tratar dos problemas básicos de saúde bucal, sucumbe diante das tentações do mercado, induzindo - habitus quem tem emprego público na área da saúde bucal a estar sempre almejando avançar na profissão, descortinando novos conhecimentos e novas práticas, sobretudo se, na atividade pública, não houver possibilidade de desenvolver a sua carreira de forma digna, com salário e vínculo empregatício adequados.

\section{A ciência odontológica, Sísifo e as "pedras (dentes) que rolam"}

O sentido da disputa transepistêmica e o "efeito camaleão" entre cirurgiões-dentistas com interesses odontológicos públicos e privados serão, nesta seção, relacionados com a situação do mito grego de Sísifo e o absurdo da vida do homem, e com a Odontologia no Brasil.

O mito de Sísifo é um ensaio filosófico escrito por Camus (2008) em 1942, em que ele introduz sua filosofia do absurdo: o do homem fútil em busca de sentido, unidade e clareza no rosto de um mundo ininteligível desprovido de Deus e eternidade. Será que a realização do absurdo exige o suicídio? O autor responde que "exige revolta" e compara o absurdo da vida do homem com a situação de Sísifo que foi condenado a repetir sempre uma mesma tarefa. Singer (2006) relaciona esse mito com o sentido da vida e com o viver com um propósito. De acordo com o antigo mito grego, Sísifo contou os segredos dos deuses aos mortais, por isso foi condenado a empurrar uma pedra gigantesca até o cimo de um monte. Quando se aproximava do cume, o esforço tornava-se demasiado para si, e a pedra descia de novo até o sopé. Sísifo, então, reiniciava a sua tarefa e o fato se repetia, obrigando-o a empurrar a pedra durante toda a eternidade.

O mito de Sísifo constitui uma "metáfora" sombria da falta de sentido na existência humana, pois trabalhamos todos os dias para nos alimentar e alimentar a nossa família, e mal uma tarefa é concluída, temos de começar tudo de novo (Singer, 2006). A trilogia cinematográfica recente de Matrix, dos irmãos cineastas Andy e Larry Wachowski, permite-nos estabelecer um olhar metafórico à prática odontológica hegemônica. O fantástico que vem à tela cinematográfica deve ser ao menos admissível da perspectiva científica, como se tudo que parece misterioso tivesse uma explicação racional (Oliveira, 2006).

Com a implantação dos Centros de Referência de Especialidades Odontológicas, pelo "Programa Brasil Sorridente", do Ministério da Saúde, instalou-se um processo que esperamos seja irreversível, na construção da universalidade odontológica no SUS. Entre as especialidades oferecidas, está a de prótese total dentária. Essa política veio ao encontro dos dados epidemiológicos do "Projeto SB Brasil 2003" (Brasil, 2004), que chamaram a atenção para o fato de que, aproximadamente, $20 \%$ da população brasileira já perderam todos os dentes, e a boca mutilada tornou-se fator de exclusão social das classes pobres (Kovaleski, Freitas, Botazzo, 2006).

O Programa Brasil Sorridente, a princípio, é muito relevante, pois inicia uma nova fase no setor público odontológico, com a adoção de procedimentos de média e alta complexidade na atenção à saúde bucal. Para melhor entendermos esse contexto, tomemos, como exemplo, a percepção do antropólogo Roberto da Matta (1987) sobre a sociedade brasileira. Ele a considera como relacional, onde o básico, o valor fundamental, é relacionar, misturar, confundir, conciliar.

A cidadania, num universo relacional, ajuda-nos a entender quem não tem acesso adequado à assistência odontológica e, quando a procura, muitas vezes o faz, dizendo: "Dotô, vim distrair meu dente com nostalgia". Assim, está alimentando o imaginário social odontológico da extração-mutilação dentária (edentulismo), levando o indivíduo a achar que os dentes são estruturas do corpo descartáveis (Emmerich, 2000). Nesse caso, a metáfora que usamos do sujeito, por sua iniquidade social e miséria humana construída historicamente, fornece o diagnóstico para o seu mal. Para esses indivíduos, extrair 
os dentes doentes e passar a usar uma dentadura deve significar a possibilidade e a mediação de uma renovação, uma "nova realidade", um órgão "novo", um novo corpo, uma "bucalidade recauchutada", mesmo que seja falso e um absurdo.

Esse modo artificial de renovação, com dentes falsos, em que muitos cidadãos-usuários estão envolvidos pelo imaginário social odontológico, e a iniquidade odontológica nos permitem aceitar que vivemos numa espécie de Matrix Odontológico (Emmerich, 2005), no qual situações artificiais e comportamentais, como usar uma prótese dentária, são impostas como algo natural. Não somos contra fornecer uma prótese total dentária, realizada com técnica adequada e gratuita para quem necessita; o que pretendemos é chamar a atenção para a mutilação social que é o absurdo odontológico da extração-dentária, sobretudo quando o dente tem uma possível recuperação.

O exemplo da inversão da realidade na prática odontológica, com a dentadura, é um fato e não uma imposição dos deuses, como o sofrimento de Sísifo. Serve como alerta para que não se crie um mundo odontológico falso e paralelo, e para que o profissional não consolide um Matrix Odontológico (Emmerich, 2005) obscurantista, dogmático, produtor de alienação. Para Kovaleski, Freitas e Botazzo (2006), ocorre, na prática odontológica, uma inversão de valores, pois a boca, que consome o mundo, agora deve ser consumida pela área do saber e pela prática odontológica direcionada ao mercado.

O corpo possuidor de uma boca desdentada, fragmentada e incompreendida transforma-se em objeto de consumo do mercado odontológico, que é um campo fértil para a propagação do "efeito camaleão" nas mentes dos cirurgiões-dentistas.

\section{Considerações finais: o camaleão olha-se no espelho}

Ao refletirmos, de forma introdutória, sobre as condições de construção, produção e apropriação do conhecimento científico odontológico e sobre o "efeito camaleão", buscamos desvelar a ininteligibilidade social que rodeia e se interpenetra na ciência odontológica na sociedade contemporânea. Procuramos romper o círculo vicioso, como diz Santos (2003a), na compreensão do real social do objeto-sujeito-objeto, ampliando o campo da compreensão, da comensurabilidade e, portanto, da intersubjetividade dialógica, pluralizando-a entre todos os atores envolvidos na "comunidade odontológica".

A instituição odontológica é uma criação da história humana, dentro da qual o peso da história e o fenômeno da alienação, como fetiche do mercado (Marx, 1987), obscurecem a associação de idéias, por exemplo, o processo de adoecimento bucal que, de modo geral, tem, dentro de si, como fatores condicionantes, as relações socioeconômicas e culturais. Botazzo (2008) assinala que há uma vantagem teórica em pensar assim, pois podemos recuperar o homem por inteiro, em sociedade, seu modo de ser, seus conflitos, sua relação com o próprio corpo e a própria boca. Para Castiel (1999), ser humano deve ser considerado em sua singularidade e em suas formas de sentir e manifestar seus mal-estares diante de si, de seu entorno, de seu psiquismo, de seu corpo ou, de modo sintético, de seu "corpsiquismo" em seu respectivo contexto.

Ao longo deste trabalho, surgem vários elementos que, de uma forma crítica, procuram explicar os labirintos da significação da vida humana (Berger \& Luckmann, 2004) e a rede de complexidade da formação identitária do cirurgião-dentista desde o seu início. Devemos ressaltar que, para os autores discutidos, na modernidade tardia, emergiu um sujeito cirurgião-dentista fragmentado, com ânsia de se tornar capaz, que procura sobreviver, muitas vezes, mimetizando-se dentro das alternativas que lhe são apresentadas na bifurcação público-privada.

A sentença do esforço interminável de extrair dentes, vista criticamente pelo trabalho de Sísifo, pode ser entendida conforme Latour (2006), quando afirma que: o crítico não é o que desmonta, mas o que monta; não é o que puxa o tapete, mas o que oferece arenas onde se pode juntar; é aquele que sabe que, se alguma coisa é construída, isso significa que é frágil e, portanto, muito necessitada de autocrítica, do cirurgião-dentista olhar-se no espelho.

Para Moysés (2004), o conhecimento odontológico está intimamente relacionado com uma ruptura na esfera pública e privada. Isso vem se expressar na falta de sentido explícito na guerra "silenciosa" 
epistêmico-odontológica que coloca a "comunidade odontológica" envolta e entrelaçada em uma arena na qual microprocessos cotidianos ricos em controvérsias geram práticas, com idéias, posturas e sentidos, mediadas pelo cirurgião-dentista e demais atores envolvidos, fazendo ainda persistir, em grande monta, a "arte dentária" como technè.

Aprofundar o diálogo dessas práticas é o caminho para superar o estágio da consciência socialodontológica na atual estrutura social; e, se quisermos conferir sentido às nossas vidas, trabalhando para uma causa, essa causa tem de ser transcendente (Singer, 2006). Portanto, uma causa que não seja egoísta, uma causa que ultrapasse os limites do nosso eu, uma causa mais vasta do que o eu, se pretendermos encontrar autoestima genuína e sermos tudo o que conseguirmos ser.

Nesse caso, seríamos realistas e críticos quanto às questões de interesse para o que a Odontologia possa vir a ser e a sociedade (como um todo). Essas questões, se, ao explicá-las, pudermos aplicá-las, quem sabe, superaremos o "efeito camaleão"?

\section{Colaboradores}

Os autores trabalharam juntos em todas as etapas de produção do manuscrito.

\section{Referências}

AGENDA Dental calendar. Rev. ABO Nac., v. 13, n.3, p. 190-1, 2006.

BERGER, P.L.; LUCKMANN, T. Modernidade, pluralismo e crise de sentido. Petrópolis: Vozes, 2004

BOURDIEU, P. Razões práticas: sobre a teoria da ação. Campinas: Papirus, 1996.

BOTAZZO, C. Integralidade da atenção e produção do cuidado: perspectivas teóricas e práticas para a ciência odontológica à luz do conceito de bucalidade. In: MACAU, M. (Org.). Saúde bucal coletiva: implementando idéias... concebendo integralidade. Rio de Janeiro: Rubio, 2008. p.3-15.

Sobre a bucalidade: notas para a pesquisa e contribuição ao debate. Cienc. Saude Coletiva, v.11, n.1, p.7-17, 2006.

Saúde bucal e cidadania: transitando entre a teoria e a prática. In: PEREIRA, A.C. (Org.). Odontologia em saúde coletiva: planejando ações e promovendo saúde. Porto Alegre: Artmed, 2003. p.17-27.

BRASIL. Programa Nacional de Reorientação da Formação Profissional em Saúde Pró-Saúde: o SUS e a formação de recursos humanos em saúde. Brasília: Ministério da Educação, 2007. Disponível em: < http://www.prosaude.org/pub/sus_frhs/ index.php>. Acesso em: 12 fev. 2007.

Ministério da Saúde. Projeto SB Brasil 2003: condições de saúde bucal da população brasileira 2002-2003: resultados principais. Brasília: SAS/DAB, 2004.

CAMUS, A. O mito de Sísifo. 5.ed. Rio de Janeiro: Record, 2008.

CANGUILHEM, G. O normal e o patológico. 6.ed. Rio de Janeiro: Forense Universitária, 2007. 
CASTIEL, L.D. Dédalo e os Dédalos: identidade cultural, subjetividade e os riscos à saúde. In: CZERESNIA, D.; FREITAS, C.M. (Orgs.). Promoção da saúde: conceitos, reflexões, tendências. Rio de Janeiro: Fiocruz, 2004. p.79-95.

Fiocruz, 1999

A medida do possível...: saúde, risco e tecnobiociências. Rio de Janeiro:

CHAVES, M.C.; MIRANDA, A.S. Discursos de cirurgiões-dentistas do Programa Saúde da Família: crise e mudança de habitus na saúde pública. Interface - Comunic., Saude, Educ., v.12, n.24, p.153-67, 2008.

DA MATTA, R. A casa \& a rua. Rio de Janeiro: Guanabara, 1987.

EMMERICH, A. Matrix odontológico. Vitória: A Gazeta, 2005. p.3.

O experimento controlado da fluoretação em Baixo Guandu. In: EMMERICH,

A.; FREIRE, A. S. (Orgs.). Flúor e saúde coletiva. Vitória: Edufes, 2003. p.44-59.

A corporação odontológica e o seu imaginário. Vitória: Edufes, 2000.

GAYON, J. Epistemología da medicina. In: RUSSO, M; CAPONI, S. (Orgs.). Estudos de filosofia e história das ciências biomédicas. São Paulo: Discurso Editorial, 2006. p.3963.

GONZÁLEZ, C.P. Es la práctica odontológica un trabajo social descontextualizado? Rev. Cuba. Estomatol., v.34, n.2, p.96-102, 1997.

HALL, S. A identidade cultural na pós-modernidade. 10.ed. Rio de Janeiro: DP\&A, 2005.

HOCHMAN, G. A ciência entre a comunidade e o mercado: leituras de Kuhn, Bourdieu, Latour e Knorr-Cetina. In: PORTOCARRERO, V. (Org.). Filosofia, história e sociologia das ciências I: abordagens contemporâneas. Rio de Janeiro: Fiocruz, 2002. p.199-231. KOVALESKI, D.F.; FREITAS. S.F.T.; BOTAZZO, C. Disciplinarização da boca: a autonomia do indivíduo na sociedade do trabalho. Cienc. Saude Coletiva, v.11, n.1, p.97-103, 2006.

LATOUR, B. O poder da crítica. Lisboa: Pretexto, 2006.

A esperança de Pandora. Bauru: EDUSC, 2001.

Ciência em ação. São Paulo: Ed. Unesp, 2000.

MARX, K. O capital. São Paulo: Bertrand Brasil, 1987.

MOYSÉS, S.J. Política de saúde e formação de recursos humanos em odontologia. Rev. ABENO, v.1, n. 4, p.30-7, 2004.

NARVAI, P.C. Saúde bucal coletiva: caminhos da odontologia sanitária à bucalidade. Rev. Saude Publica, v.40, p.141-7, 2006.

Recursos humanos para promoção da saúde bucal: um olhar no início do século XXI. In: KRIGER, L. (Coord.). ABOPREV. 3.ed. São Paulo: Artes Médicas, 2003. p.475-94.

OLIVEIRA, B.J. Cinema and the scientific imaginary. Hist. Cienc. Saúde -Manguinhos, v.13, suppl, p.133-50, 2006.

SANTOS, B.S. Um discurso sobre as ciências. 14.ed. Porto: Afrontamento, 2003a. Introdução a uma ciência pós-moderna. 4.ed. São Paulo: Graal, 2003 b.

SENNETT, R. A cultura do novo capitalismo. Rio de Janeiro: Record, 2006.

SINGER, P. Como havemos de viver? Lisboa: Dinalivro, 2006.

SOCHA, E. Um esporte de combate. Cult, v.11, n.128, p.44-46, 2008. 
UNIVERSIDADE DE BRASÍLIA. Cursos. Odontologia: senso estético e compromisso social. Disponível em: <http://www.unb.br/graduaçao/cursos/sobre/odonto.php.>. Acesso em: 9 out. 2008.

WARMLING, C.M.; CAPONI, S.; BOTAZZO, C. Práticas sociais de regulação da identidade do cirurgião-dentista. Cienc. Saude Coletiva, v.11, n.1, p.115-22, 2006.

EMMERICH, A.; CASTIEL, L.D. La ciencia odontológica, Sísifo y el "efecto camaleón". Interface - Comunic., Saúde, Educ., v.13, n.29, p.339-51, abr./jun. 2009.

La ciencia odontológica no está aislada del contexto social al que se vincula. Este artículo describe la ciencia odontológica tal como se presenta en el proceso de gradiación de los cirujanos-dentistas, haciendo una crítica sobre el papel del conocimiento científico y de sus relaciones con la práctica de sus principales actores en la bifurcación pública y privada. A partir de la formación académica, en el periodo de transición entre la Academia y el mercado de trabajo, trata de entender las razones por las cuales el conocimiento se produce y se transforma por el mimetismo de los varios papeles odontológicos dados por el "efecto camaleón". Concluye que en esta arena trans-epistemológica la controversia es normal y el interés en cunto a su destino está en nustras manos. Procura ser realista y crítico en relación a las cuestiones de interés para oa Odontología y la sociedade si, al explicarlas, podemos aplicarlas y quizás superar el "efecto camaleón".

Palabras clave: Arena trans-epistemológica. Ciencia odontológica. Odontología y sociedad. 